\title{
IDENTIDADE, EXPERIÊNCIA E SABERES \\ DOS HOMENS DE COR NO MERCADO DE TRABALHO \\ DO RECIFE OITOCENTISTA
}

MAC CORD, Marcelo. Artífices da cidadania: mutualismo, educação e trabalho no Recife oitocentista. Campinas: FAPESP/Editora da Unicamp, 2012. 440p.

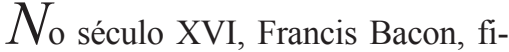
lósofo, político e ensaísta inglês, se ocupou especialmente de explicar o empirismo como método científico. Segundo ele, o trabalho manual não estava dissociado do pensamento racional; ao contrário, experiência e reflexão sustentavam o conhecimento. $\mathrm{O}$ pensamento de Bacon tem efeito ao ser apresentado logo na introdução do livro de Marcelo Mac Cord, que tem como tema a história de um grupo de homens de cor, artífices, identificados como aqueles que exerciam trabalhos manuais, mecânicos e que, no Brasil ainda escravocrata do século XIX, construíram seu espaço na sociedade, apesar de todas as restrições que lhes eram impostas. Fomentaram instituições profissionais e educacionais, fortalecendo-se paulatinamente e demostrando uma "coesão de classe", como diria Eric Hobsbawm. ${ }^{1}$ Ou seja, estiveram
\end{abstract}

Eric J. Hobsbawm, Mundos do trabalho: novos estudos sobre a história operária. $3^{\mathrm{a}}$ ed. rev. São Paulo, Paz e Terra, 2000, p.39. atentos às conquistas que poderiam requalificar sua imagem, sua posição social e engendrar um futuro mais digno aos seus descendentes; e agremiaram-se para o seu fortalecimento individual e coletivo, despontando como corpo social. O que não lhes faltou foram experiência $\mathrm{e}$ reflexão.

Contudo, ainda no século XIX, prevalecia o pensamento de que as atividades manuais não requeriam esforço intelectual, sendo próprias de um adestramento mecânico inerente aos indivíduos das classes subalternas. A oposição entre "artes liberais" e "artes mecânicas" desdobrou-se para além dos produtos oriundos de cada uma dessas áreas, pautou-se em dicotomias socioeconômicas: operários e patrões, plebeus e nobres, escravos e senhores. No entanto, sempre houve circularidade e contradições, sendo esses atributos inerentes a qualquer construção histórica que queira nos aproximar do passado. E isso Marcelo Mac Cord nos apresenta em cinco capítulos com um texto bem escrito, 
instigante, oferecendo ao leitor uma narrativa que passou despercebida pela historiografia brasileira e tem florescido nas últimas décadas.

O grupo de indivíduos sobre o qual o foco da obra recai era especializado em construir edificações no Recife. Os pioneiros estiveram matriculados na Irmandade de São José do Ribamar, que, desde os finais do século XVIII, agremiava pedreiros, carpinteiros, marceneiros e tanoeiros. Aglutinar-se em confrarias religiosas era uma prática conhecida, advinda dos antigos artesãos da Idade Média. Eles eram integrantes das classes menos abastadas, embora à época alguns indivíduos alcançassem, por meio do ofício, reconhecimento, posses e ascendência social. A implantação do sistema corporativo português no Brasil foi adaptada à estrutura social vigente, não sendo difícil imaginar o quanto os mestres de ofício estrangeiros que aqui chegavam se beneficiaram com a aquisição de escravos, ensinando-lhes o ofício, o que permitia que se libertassem da posição de executores para se dedicar a outras investidas, como buscar serviços. Esse foi um processo natural. No Brasil, pouco efeito teve a extinção oficial das corporações em 1824, e, com isso, a perda do monopólio dos mestres em controlar os mercados. Como salienta Mac Cord, a posição dos mestres de ofício estrangeiros se elevava na proporção dos oficiais que tinham sob seu comando e na medida em que suas mãos se livra- vam dos instrumentos, pesos e lidas manuais. Ocupar-se de executar ou consertar artefatos passaria a ter outro significado. E, assim, os homens de cor, alforriados ou nascidos livres, por todo o Brasil, abraçaram as artes mecânicas, tornam-se mestres de ofício, oficiais mecânicos e aprendizes do ofício, numa escala hierárquica que combinava experiência e saberes.

No capítulo 1, o autor analisa os meandros que instruíram a fundação e o funcionamento da Sociedade das Artes Mecânicas, agremiação laica estabelecida em 1841, na cidade do Recife, por mestres carpinas e pedreiros. Junto à Irmandade de São José do Ribamar, a sociedade foi um lugar para a formação de suas identidades, que se forjaram para enfrentamentos de disputas, não só de mercado de trabalho, como por posições sociais. Marcelo Mac Cord fez uma pesquisa minuciosa sobre os indivíduos envolvidos na constituição da sociedade e seus objetivos principais - auxílio mútuo e instrução - , a partir de diversos arquivos. Suas fontes foram produzidas não só pelos próprios artífices, mas pelo governo, pelas elites letradas e proprietárias de Pernambuco. Daí emergem, no seu texto, os artífices e suas motivações para aglutinaremse em defesa dos seus interesses e os apoios que tiveram de buscar em diversos setores sociais para o fortalecimento da entidade que criaram. Nesse contexto, o autor constrói a história de um mestre carpina, José 
Vicente Ferreira Barros, sua família e companheiros. Ele fora o idealizador da Sociedade das Artes Mecânicas e de tantas outras estratégias de sobrevivência numa sociedade escravocrata e racista.

O Recife de então é retratado por Mac Cord a partir das nuances sociais e políticas compreendidas nas narrativas que tratam da própria associação, seus eventos, suas transformações. Por ter traçado a trajetória de José Vicente Ferreira Barros e seus filhos, as experiências de vida de seus membros podem ser acompanhadas. Assim, a obra esclarece não só a história da organização de trabalhadores de cor em agremiações profissionais e educacionais, mas traz ao texto seus protagonistas, seus valores e ideais, indicando como ocorreram entrelaçamentos com outros personagens da sociedade recifense de então. Como bem ressalta Silvia Lara no prefácio da edição:

[...] seguindo as lições de Marc Bloch, Marcelo Mac Cord prestou atenção aos homens, no plural, produzindo uma narrativa em que podemos reconhecer gente de carne e osso, com valores e expectativas que moldavam suas vidas familiar, social, política e profissional. Seguindo as lições de Edward P. Thompson, prestou atenção ao fato de que essas ideias e esses valores não eram únicos naquele mundo: os sentimentos de orgulho, dignidade, precisão e inteligência que governavam suas vidas profissionais tinham que lidar com as ideias de "progresso" e "civilização" que eram apregoadas em várias situações por políticos e administradores (p.24).

O livro se ancora, como já dito, no mestre carpina José Vicente Barros, um líder entre os seus, que não se intimidou frente aos novos ideais de "progresso" e "civilização" que despontavam nos discursos morigerados dos governos. $\mathrm{O}$ autor analisa como ele e seu grupo se apropriaram do mesmo discurso, estabelecendo objetivos, propondo o aperfeiçoamento de seus associados, tendo incluído no escopo de suas atividades aulas noturnas de caráter "teórico" como uma maneira de evidenciar que não estavam restritos à prática. Concomitantemente, introduziram um sistema mutualista na sociedade: concediam pecúlios, amparavam viúvas e órfãos, faziam funerais e iam além, captando serviços para o provimento dos seus sócios. Políticos locais passaram a fazer contribuições financeiras e exaltaram o bom exemplo dado pela instituição. Essa atitude, ante a legislação que proibia o tráfico negreiro, ao chamado que o Brasil recebeu para participar da Exposição Universal, ${ }^{2}$ os novos ideais de modernidade baseados na técnica e na instrução e o grande te-

As exposições universais despontam no século XIX como vitrines para os acervos de vários países. Tinham como objetivo a propaganda positiva da sociedade burguesa capitalista que, sobretudo, estaria implantando a modernização e as inovações tecnológicas. 
mor das insurgências das camadas pobres, abriu um campo profícuo ao entendimento com o governo da província, que passou a exaltá-los como modelo a ser seguido.

$\mathrm{O}$ autor avalia esse processo no capítulo 2, revelando outras estratégias dos artífices em busca de afirmação social, como a mudança de nome da associação e a implementação de um novo estatuto, dez anos após a sua fundação. Em 1851, a instituição passou a ser a Sociedade das Artes Mecânicas e Liberais, tentando denotar suas aptidões para um campo antes exclusivo dos indivíduos mais abastados, tidos na sociedade de então como cultos e inteligentes. No âmbito dessa mudança, aproximaram-se das elites letradas e proprietárias, passando a matricular na sociedade "toda a classe artística" (p.31). Isso contribuiu para a mudança do status social dos artífices, conferindo-lhes novas oportunidades, alguns mestres tornando-se sócios em empreitadas governamentais. Assim, Marcelo Mac Cord revela a presença de pretos e mestiços atuando profissionalmente como executores, projetistas e empreiteiros em obras públicas e frequentando escolas primárias e secundárias na cidade. Os que alcançavam a categoria de mestres tinham sob seu comando aprendizes e serventes, chegando a lavrar contratos que conferiam confiabilidade na transação e reforçavam o caráter de dignidade que haviam construído sobre si.

Não demorou para que os em- bates surgissem, pois o crescimento e prestígio da sociedade e do grupo já eram notórios. E eles começaram entre os artífices. A Irmandade de São José do Ribamar, que os havia acolhido em sua sede, não cedeu mais o espaço físico que a sociedade requeria para continuar crescendo. Apesar de muitos confrades serem também sócios, foi inevitável o rompimento, e a sociedade foi expulsa do espaço da igreja.

Mac Cord reconstrói o período de dificuldades enfrentadas pela sociedade depois dessa ruptura e demostra como as ligações que alguns sócios mais abastados mantinham com a rede de empreendedores da cidade os manteve atuantes. Nesse novo tempo, políticos e empreiteiros são descobertos pelo pesquisador nos quadros de sócios honorários e beneméritos da instituição, o que os aproximava das oportunidades de mercado, especialmente as edificações públicas; revela-se, então, o "espírito de empresa" dos artífices (p.39). Essa transição é discutida no capítulo 3, que trata dos novos rumos da sociedade.

Já no capítulo 4, os conflitos e consequências dessas mudanças são rastreados pelo autor. Afinal, nem todos os que pertenciam ao quadro de sócios foram alocados nas melhores oportunidades que surgiam; houve artífices menos afortunados em seus projetos que se sentiram descontentes e seguiram por novas trilhas. Sobraram poucos sócios a serem aperfeiçoados. Houve 
uma redução nas aulas noturnas, os discentes passaram a ser em menor número $\mathrm{e}$, consequentemente, não viriam a compor o quadro de associados. De acordo com o autor, "o descaso com o mutualismo e com o 'aperfeiçoamento' dos sócios certamente contribuiu para o gradativo desinteresse de artífices recifenses pela Sociedade." (p.295) Enquanto a Sociedade dos Artistas Mecânicos e Liberais perdia força institucional, um pequeno grupo de artistas mecânicos de pele escura escapou da proletarização da categoria, capitalizou vantagens e nela se manteve, apesar de a entidade ter passado a agregar sócios abastados. Entretanto, o mercado pernambucano não era o mesmo, já contava, então, com capitalistas desvinculados das práticas corporativas.

Demandas sociais passaram a incentivar a "instrução popular" por meio de um discurso que enaltecia a qualificação, a necessidade de modernização do país, embora o não dito incluísse a intenção de aplacar possíveis descontroles sociais. É no bojo dessas intenções que se consolidou o Liceu de Artes e Ofícios do Recife. Quase fechando as portas e com seus velhos mestres afastados do poder, a sociedade os recolocaria em posições de comando e aceitaria o convite para tornar-se mantenedora do liceu, pois, afinal, dispunha de material humano com experiência suficiente para a prática pedagógica requerida. Intencionavam sem- pre avançar em espaços a que antes não tinham acesso, monopolizar o ensino das artes mecânicas, reconfigurando o mercado de trabalho; em consequência, teria mais status aquele que se diplomasse. Mac Cord esmiúça essa nova conjuntura. Em 1870, a sociedade recebeu o título de "Imperial" e foi impelida a uma nova reconfiguração, aumentou significativamente o número de matriculados, mas não conseguiu dar conta do propósito fulcral, baseado em seus costumes e marcado pelo binômio auxílio mútuo e instrução. O autor nos mostra como os laços já arraigados entre os antigos mestres e políticos locais acabaram por alocar os artífices em obras públicas, distanciando-os do ofício de transmitir conhecimento e experiências, restando à sociedade encarar o papel de empreiteira, mais uma em meio a tantas outras que já existiam no mercado recifense.

No tocante aos debates com a historiografia social do trabalho, os resultados da pesquisa de Mac Cord contrastam bem com algumas interpretações que antecederam sua obra. A primeira é a de que, com o fim das corporações de ofício no Brasil, os trabalhadores passaram "naturalmente" a fundar associações laicas, com caráter unicamente profissional. Na sua pesquisa, acompanha-se a história da atuação conjunta, conquanto nem sempre cooperativa, da irmandade com a sociedade até meados de 1860. O autor salienta que a confraria permaneceu respondendo 
aos anseios de alguns grupos de artífices e, sobretudo, demonstra que não houve, no caso do Recife, uma mudança abrupta das "arcaicas" confrarias pelas "modernas" associações. E assim também ressalta o cuidado que se deve ter com a ideia de transição entre um suposto "período mutualista" para uma "primeira fase do movimento sindical brasileiro", como está colocado em livros clássicos sobre a história do trabalho no Brasil (p.33).

Mac Cord problematiza essa e outras questões, não se atendo a interpretações generalizantes, que não enxergaram mobilidades sociais ascendentes conquistadas por afrodescendentes. Sua pesquisa em muito contribui para a historiografia sobre a identidade dos trabalhadores no período imperial por revelar experiências fundamentais dos homens de cor, os tipos de associações que conceberam, a importância que conferiram à qualificação por meio dos estudos, bem como sua apropriação do sistema mutualista antes da Abolição.

Artifices da cidadania: mutualismo, educação e trabalho no Recife oitocentista é apresentado segundo a periodização atravessada pela sociedade, seus sujeitos, os fenômenos sociais e culturais que se desenvolveram. Marcelo Mac Cord foi um artífice no trabalho de construção dessa obra. Como ele mesmo menciona, os métodos e caminhos que perseguiu se assemelham àqueles dos antigos mestres artesãos. Erigiu uma obra com arte e técnica. Sem esgotar o assunto, abre perspectivas para novas investigações, que não podem prescindir do referido livro para a compreensão do mundo do trabalho no Brasil.

Lysie Reis lysie60@hotmail.com Universidade do Estado da Bahia 